\title{
Phylogenetic structure of the Sporopachydermia cereana species complex
}

\author{
Marc-André Lachance, ${ }^{1}$ Jody E. Kaden, ${ }^{1}$ Herman J. Phaff ${ }^{2}$ \\ and William T. Starmer ${ }^{3}$
}

Author for correspondence: Marc-André Lachance. Tel: +1 519661 3752. Fax: +1 5196613935.

e-mail: lachance@julian.uwo.ca

\footnotetext{
1 Department of Plant Sciences, University of Western Ontario, London, Ontario, Canada N6A 5B7

2 Department of Food Science and Technology, University of California, Davis, CA 95616, USA

3 Department of Biology, Syracuse University, Syracuse, NY 13244, USA
}

\begin{abstract}
A large number of isolates previously referred to as members of the 'Sporopachydermia cereana species complex' were examined by various DNA characterization methods, leading to the conclusion that the complex is in fact made up of 10 species, one of which contains three varieties. The sequences of the internal transcribed spacer (ITS) region and the D1/D2 divergent domains of the large subunit rDNA were determined for representatives of each taxon and specific primers based on differences in the ITS were designed for rapid identification of five of the taxa. Whereas the data provide additional elements for the calibration of the ITS as a criterion for species delineation, the emerging pattern is that the ITS region does not function as well as the D1/D2 domains as an evolutionary clock. Some taxa appear to be specific for the geographical regions where they were isolated, and the distribution of many taxa is mutually exclusive.
\end{abstract}



\section{INTRODUCTION}

Lachance \& Phaff (1998) accepted three species in the genus Sporopachydermia. They cautioned that one of these, Sporopachydermia cereana, is difficult to identify by conventional methods, as it is part of a complex of cryptic species. The expression 'Sporopachydermia cereana species complex' (Lachance et al., 1988; Starmer et al., 1990) has been used to designate the large number of isolates from necrotic cactus tissue that share with Sporopachydermia cereana the ability to assimilate inositol and erythritol as carbon sources. Collectively, these represent the third most abundant component of the cactophilic yeast community. In this paper, we extend the use of that term to refer to any taxon that is difficult to differentiate from Sporopachydermia cereana by morphological and nutritional characters and we shall adopt the expression 'Sporopachydermia clade' to designate the entire genus and related asexual species. Over a 25-year period, we have examined a large number of isolates at the levels of morphology, physiology, DNA base composition,

Abbreviations: $C T A B$, cetyldimethylethylammonium bromide; ITS, internal transcribed spacer.

The GenBank accession numbers for the sequences reported in this paper are AF202900-AF202921.
DNA-DNA reassociation, electrophoretic karyotyping and rDNA sequencing and have found that the complex is in fact an assemblage of several genetically distinct taxa. The phylogenetic structure of the clade has been clarified by rDNA sequencing. We now report these results.

\section{METHODS}

Micro-organisms. The strains used in this study (Table 1) were collected during various expeditions to study the ecology and biodiversity of yeasts associated with cacti and other sources by us or by other colleagues. Identification followed standard methods (Yarrow, 1998) as modified for cactophilic yeasts (Lachance et al., 1988).

Assessment of sporulation, mating and inhibition reactions. Sporulation was assessed on McClary's acetate agar. In order to detect sporulation that arises after conjugation, cells were first mixed and incubated for $2 \mathrm{~d}$ on corn meal agar (Difco) and then transferred to acetate agar. The presence of conjugation figures or ascospores was assessed by light microscopy. Inhibition of strains by other strains in the Sporopachydermia cereana complex was assessed by inoculating potential inhibitor cultures as spots on lawns of potentially sensitive cultures and observing the formation of clearing zones. The medium was YM agar (Difco) buffered to $\mathrm{pH} 5.0$ with $0.01 \mathrm{M}$ sodium acetate.

DNA characterization. Extraction and purification of DNA, determination of $\mathrm{mol} \% \mathrm{G}+\mathrm{C}$ content of DNA by ultra- 
Table 1. List of strains used in this study

DNA group-specific primer responses are given where available. Strains that induced (I) or were susceptible to (S) $\mathrm{G}_{1}$ arrest, strains whose ITS or D1/D2 sequences were determined (Sequenced) and sporulating strains (Sp) are identified. Strains the

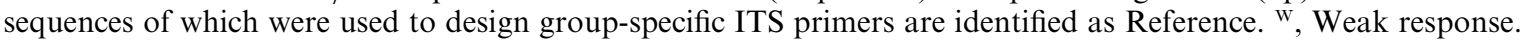

\begin{tabular}{|c|c|c|c|c|}
\hline Strain & Source & Primer & $G_{1}$ arrest & Remarks \\
\hline \multicolumn{5}{|l|}{ S. cereana } \\
\hline D72-313 & Carnegiea gigantea, Arizona, USA & IT3 & & Reference \\
\hline D76-214C & Stenocereus thurberi, Baja California, Mexico & IT3 & & $\mathrm{Sp}$ \\
\hline D76-406C & Rathbunia sp., Sonora, Mexico & IT3 & $\mathrm{S}^{\mathrm{w}}$ & $\mathrm{Sp}$ \\
\hline D81-413C & Opuntia phaeacantha, Arizona, USA & & & \\
\hline D81-489B & Opuntia ficus-indica, Arizona, USA & IT3 & I & \\
\hline D81-676.2 & Opuntia lindheimeri, Texas, USA & & & \\
\hline W84-201.4 & Opuntia phaeacantha, Arizona, USA & IT3 & $\mathrm{S}$ & \\
\hline W84-211.2 & Opuntia phaeacantha, Arizona, USA & IT3 & & \\
\hline W84-233 & Opuntia phaeacantha, Arizona, USA & IT3 & & \\
\hline W84-213.2 & Carnegiea gigantea, Arizona, USA & IT3 & & \\
\hline W84-238.2 & Opuntia phaeacantha, Arizona, USA & IT3 & I & \\
\hline W85-212.4 & Opuntia phaeacantha, Arizona, USA & IT3 & & \\
\hline W85-814.2 & Opuntia phaeacantha, Arizona, USA & IT3 & & $\mathrm{Sp}$ \\
\hline W85-837.2 & Carnegiea gigantea, Arizona, USA & IT3 & & \\
\hline W87-2305.2 & Opuntia ficus-indica, Island of Maui, Hawaii, USA & IT $7^{\mathrm{w}}$ & I & Sp, Sequenced \\
\hline W87-2326.3 & Opuntia ficus-indica, Island of Maui, Hawaii, USA & IT7 ${ }^{\mathrm{w}}$ & $\mathrm{I}, \mathrm{S}^{\mathrm{w}}$ & \\
\hline W87-2350.2 & Opuntia ficus-indica, Island of Maui, Hawaii, USA & IT7 ${ }^{\mathrm{w}}$ & $\mathrm{I}$ & \\
\hline W87-2411.2 & Opuntia ficus-indica, Island of Maui, Hawaii, USA & IT7 ${ }^{\mathrm{w}}$ & $\mathrm{S}$ & \\
\hline \multicolumn{5}{|l|}{ 'oaxacaensis' } \\
\hline D77-321B & Cactus, Oaxaca, Mexico & IT7 & & Homologous \\
\hline S84-554.2 & Stenocereus pruinosus, Tehuacan, Mexico & IT7 & & \\
\hline S84-567.2 & Estontria chiotilla, Tehuacan, Mexico & IT7 & & \\
\hline S84-575.2 & Estontria chiotilla, Tehuacan, Mexico & IT7 & & \\
\hline S87-475.1 & Opuntia (Nopalea) sp., Oaxaca, Mexico & IT7 & $\mathrm{S}$ & $\mathrm{Sp}$ \\
\hline S87-477.1 & Opuntia (Nopalea) sp., Oaxaca, Mexico & IT7 & $\mathrm{I}, \mathrm{S}^{\mathrm{w}}$ & \\
\hline S87-478.2 & Opuntia (Nopalea) sp., Oaxaca, Mexico & IT7 & $\mathrm{S}$ & \\
\hline S87-479.2 & Stenocereus pruinosus, Oaxaca, Mexico & IT7 & $\mathrm{S}$ & \\
\hline S87-487.2 & Opuntia (Nopalea) sp., Oaxaca, Mexico & IT7 & I & \\
\hline S87-507.2 & Stenocereus pruinosus, Chiapas, Mexico & IT7 & $\mathrm{S}, \mathrm{I}^{\mathrm{w}}$ & \\
\hline S87-524.1 & Stenocereus pruinosus, Chiapas, Mexico & IT7 & $\mathrm{S}, \mathrm{I}^{\mathrm{w}}$ & \\
\hline \multicolumn{5}{|c|}{ 'stenocereana' } \\
\hline D82-449B & Stenocereus hystrix, Haiti & - & & Sp, Sequenced \\
\hline \multicolumn{5}{|l|}{ 'obscura' } \\
\hline D82-520A & Opuntia moniliformis, Dominican Republic & IT5 & & Reference \\
\hline S82-496A & Stenocereus hystrix, Dominican Republic & IT5 & & \\
\hline S84-553.3 & Stenocereus pruinosus, Tehuacan, Mexico & IT5 & & \\
\hline S84-566.3 & Estontria chiotilla, Tehuacan, Mexico & IT5 & & \\
\hline S86-298 & Cephalocereus lanuginosus, Barquisimeto, Venezuela & IT5 & & Sequenced \\
\hline S87-461.1 & Stenocereus sp., Oaxaca, Mexico & IT5 & & Sequenced \\
\hline S87-468.1 & Stenocereus sp., Oaxaca, Mexico & IT5 & & \\
\hline W91-476.2 & Opuntia quimilo, Argentina & IT5 & & Sequenced \\
\hline \multicolumn{5}{|l|}{ 'australis' } \\
\hline S86-297 & Cephalocereus lanuginosus, Prudencio, Venezuela & IT6 & & \\
\hline S86-303 & Acanthocereus sp., Prudencio, Venezuela & IT6 & & \\
\hline S86-314 & Opuntia wentiana, Prudencio, Venezuela & IT6 & & \\
\hline S86-358 & Cereus repandus, Barquisimeto, Venezuela & IT6 & & \\
\hline W91-460.3 & Opuntia tilcarensis, Argentina & IT6 ${ }^{\mathrm{w}}$ & I & Sequenced \\
\hline W91-478.1 & Opuntia quimilo, Argentina & IT6 & $\mathrm{I}, \mathrm{S}^{\mathrm{w}}$ & Reference \\
\hline W91-480.2 & Opuntia ficus-indica, Argentina & IT6 & $\mathrm{I}, \mathrm{S}^{\mathrm{w}}$ & \\
\hline W91-486.2 & Opuntia quimilo, Argentina & IT6 & I & \\
\hline
\end{tabular}


Table 1 (cont.)

\begin{tabular}{|c|c|c|c|c|}
\hline Strain & Source & Primer & $\mathrm{G}_{1}$ arrest & Remarks \\
\hline W91-487.1 & Opuntia quimilo, Argentina & IT6 & & \\
\hline C91-1243 & Pilosocereus arrabidae, Brazil & IT6 & & \\
\hline C91-1407 & Pilosocereus arrabidae, Brazil & & $\mathrm{S}$ & \\
\hline \multicolumn{5}{|l|}{ ‘opuntiana' } \\
\hline D77-33 & Opuntia stricta, Australia & IT $4^{\mathrm{w}}$ & $\mathrm{S}^{\mathrm{w}}$ & Sequenced \\
\hline D78-516D & Opuntia stricta, Australia & & & \\
\hline D79-101A & Opuntia stricta, Australia & & & \\
\hline D81-645.3 & Opuntia lindheimeri, Texas, USA & $\mathrm{IT}^{\mathrm{w}}$ & & \\
\hline D82-424A & Opuntia moniliformis, Haiti & IT $4^{\mathrm{w}}$ & $\mathrm{S}$ & Sequenced \\
\hline S82-450B & Stenocereus hystrix, Haiti & IT4 & & \\
\hline S82-459B & Opuntia moniliformis, Haiti & IT4 & & \\
\hline D82-461A & Opuntia moniliformis, Haiti & IT4 & I & Reference \\
\hline S82-501B & Stenocereus hystrix, Dominican Republic & IT4 & & \\
\hline S82-504B & Stenocereus hystrix, Dominican Republic & IT4 & & \\
\hline S82-508B & Stenocereus hystrix, Dominican Republic & IT4 & & \\
\hline D82-571B & Opuntia stricta, Montserrat & $\mathrm{IT}^{\mathrm{w}}$ & & \\
\hline S82-572B & Stenocereus hystrix, Dominican Republic & IT4 & & \\
\hline S82-608C & Cephalocereus royenii, Virgin Islands & IT4 & & \\
\hline D82-611C & Cephalocereus royenii, Montserrat & & & \\
\hline S82-638C & Melocactus intortus, Virgin Islands & IT4 & & \\
\hline D82-646C & Melocactus intortus, Virgin Islands & & & \\
\hline S82-653B & Cephalocereus royenii, Virgin Islands & & & Sequenced \\
\hline W83-1037.3 & Drosophila mulleri, Opuntia stricta, Jamaica & $\mathrm{IT}^{\mathrm{w}}$ & $\mathrm{I}^{\mathrm{w}}$ & \\
\hline W83-1042.4 & Drosophila stalkeri, Opuntia stricta, Jamaica & $\mathrm{IT}^{\mathrm{w}}$ & & \\
\hline S86-242 & Neoraimondia sp., Peru & & & Sequenced \\
\hline G90-209.3 & Stenocereus sp., Antigua & $\mathrm{IT}^{\mathrm{w}}$ & & \\
\hline G90-400.2 & Opuntia stricta, Florida, USA & IT $^{\mathrm{w}}$ & $\mathrm{I}^{\mathrm{w}}$ & $\mathrm{Sp}$ \\
\hline W90-1004.2 & Opuntia stricta, Ship Channel Cay, Bahamas & $\mathrm{IT}^{\mathrm{w}}$ & & \\
\hline W90-1029.2 & Opuntia stricta, Hawksbill, Bahamas & $\mathrm{IT}^{\mathrm{w}}$ & & \\
\hline W90-1033.3 & Opuntia moniliformis, Richard's Rock, Bahamas & $\mathrm{IT}^{\mathrm{w}}$ & & \\
\hline W90-1041.2 & Opuntia stricta, Long Cay, Bahamas & $\mathrm{IT}^{\mathrm{w}}$ & I & \\
\hline W90-1043.2 & Opuntia stricta, Long Cay, Bahamas & $\mathrm{IT}^{\mathrm{w}}$ & & \\
\hline W90-1054.2 & Opuntia stricta, Hall's Pond Cay, Bahamas & IT4 ${ }^{\mathrm{w}}$ & $\mathrm{S}$ & \\
\hline W90-1115.1 & Opuntia stricta, Conception Island S., Bahamas & $\mathrm{IT}^{\mathrm{w}}$ & & \\
\hline W90-1136.2 & Opuntia stricta, Conception Island N., Bahamas & $\mathrm{IT}^{\mathrm{w}}$ & & \\
\hline W90-1156.1 & Opuntia stricta, Little Torch Key, Florida, USA & IT $^{\mathrm{w}}$ & & \\
\hline W93-333.2 & Opuntia stricta, Alderlay Cay, Bahamas & $\mathrm{IT}^{\mathrm{W}}$ & & \\
\hline W93-357.5 & Opuntia stricta, Conception Island N., Bahamas & $\mathrm{IT}^{\mathrm{w}}$ & & \\
\hline W95-917.3 & Opuntia stricta, Australia & $\mathrm{IT}^{\mathrm{w}}$ & & \\
\hline \multicolumn{5}{|c|}{ 'trichocereana' } \\
\hline W91-449.2 & Trichocereus pasacana, Argentina & - & & $\mathrm{Sp}$ \\
\hline W91-456.2 & Trichocereus pasacana, Argentina & - & I & Sp, Sequenced \\
\hline \multicolumn{5}{|l|}{ 'centralis' } \\
\hline S94-304.2 & Opuntia vulgaris, Honduras & - & & Sequenced \\
\hline S94-310.1 & Opuntia guatemalensis, Honduras & - & & Sequenced \\
\hline S94-313.1 & Opuntia guatemalensis, Honduras & - & & Sequenced \\
\hline S87-428.4 & Opuntia (Nopalea) sp., Chiapas, Mexico & - & & Sequenced \\
\hline \multicolumn{5}{|l|}{ 'brasiliensis' } \\
\hline C90-399 & Pilosocereus arrabidae, Brazil & - & & Sequenced \\
\hline C90-1001 & Pilosocereus arrabidae, Brazil & - & & \\
\hline C91-1764 & Pilosocereus arrabidae, Brazil & - & $\mathrm{S}^{\mathrm{w}}$ & \\
\hline \multicolumn{5}{|c|}{ 'pachycereana' } \\
\hline D76-228A & Pachycereus pringlei, Baja California, Mexico & - & & Sequenced \\
\hline
\end{tabular}


Table 1 (cont.)

\begin{tabular}{|c|c|c|c|c|}
\hline Strain & Source & Primer & $\mathrm{G}_{1}$ arrest & Remarks \\
\hline \multicolumn{5}{|l|}{ 'agaves' } \\
\hline W92-213.4 & Agave tequilana, Jalisco, Mexico & - & & \\
\hline W92-217.3 & Agave tequilana, Jalisco, Mexico & - & & \\
\hline W94-257.2 & Agave tequilana, Jalisco, Mexico & - & & Sequenced \\
\hline W94-279.2 & Agave tequilana, Jalisco, Mexico & - & & \\
\hline \multicolumn{5}{|c|}{ 'paraquercuum' } \\
\hline W91-110.1 & Quercus rubra, Ontario, Canada & - & & Sequenced \\
\hline \multicolumn{5}{|l|}{ S. lactativora } \\
\hline CBS $6989^{\mathrm{T}}$ & Hybrid culture & - & & Sequenced \\
\hline \multicolumn{5}{|l|}{ S. quercuum } \\
\hline $\mathrm{W} 80-118^{\mathrm{T}}$ & Quercus rubra, Ontario, Canada & - & & Sequenced \\
\hline
\end{tabular}

Table 2. List of oligonucleotides used as primers in this study

Calculated annealing temperatures $\left(T_{\mathrm{m}}\right)$ are given $\left({ }^{\circ} \mathrm{C}\right)$. LSU, Large subunit; SSU, small subunit.

\begin{tabular}{|c|c|c|c|}
\hline Primer & Sequence $\left(5^{\prime}\right.$ to $\left.3^{\prime}\right)$ & $T_{\mathrm{m}}$ (hybrid) & Remarks \\
\hline $\mathrm{NL} 1 *$ & GCATATCAATAAGCGGAGGAAAAG & $52 \cdot 0$ & $5^{\prime}$ end of LSU D1, forward \\
\hline NL4* & GGTCCGTGTTTCAAGACGG & $52 \cdot 1$ & 3' end of LSU D2, reverse \\
\hline $\mathrm{IT} 1 \dagger$ & TAGGTGAACCTGCGGAAGGATCAT & $55 \cdot 4$ & $3^{\prime}$ end of SSU, forward \\
\hline IT $2 *$ & СТTTTCСТCCGCTTATTGATATGC & $52 \cdot 0$ & $5^{\prime}$ end of LSU D1, reverse complement of NL1 \\
\hline IT3 & GCAATCACTGGCTTAACAGATGT & $51 \cdot 6$ & ITS2, forward, strain D72-313 $3^{\mathrm{T}}$ (S. cereana) \\
\hline IT4 & CTGGCTGAAGAATATCCTCCAG & $53 \cdot 1$ & ITS1, reverse, strain D82-461A ('opuntiana') \\
\hline IT5 & ACCCATCGCTGGCTTTTTGAGAT & $53 \cdot 4$ & ITS2, forward, strain D82-520A ('obscura') \\
\hline IT6 & GCTAGAGAAATTGTCTCCAGCC & $53 \cdot 1$ & ITS1, reverse, strain 91-478.1 ('australis') \\
\hline IT7 & GTGATCACTGGCTTATGAGATGATAGTCT & $56 \cdot 2$ & ITS2, forward, strain D77-321B ('oaxacaensis') \\
\hline
\end{tabular}

* Primer sequence taken from O’Donnell (1993).

$\dagger$ Designed by alignment of the complete rDNA sequences of Saccharomyces cerevisiae (GenBank accession nos U53879 and Y13138) and Schizosaccharomyces pombe (GenBank accession no. Z19578).

centrifugation in $\mathrm{CsCl}$ and assessment of DNA reassociation by separation on hydroxyapatite were performed as described by Price et al. (1978), except that reference DNAs were labelled by radioiodination (Holzschu et al., 1979).

Electrophoretic karyotyping. Cells were harvested from YM agar, washed in 0.05 M EDTA ( $\mathrm{pH} 8)$ and adjusted to an optical density $(660 \mathrm{~nm})$ of 20 . The cells were diluted $1: 1$ with 0.05 M EDTA and molten agarose (low-melting-point, Bio-Rad; final concentration $1 \%$ in $0.05 \mathrm{M}$ EDTA) and poured into moulds. The agarose blocks were incubated overnight at $37^{\circ} \mathrm{C}$ in buffered Pronase as recommended by McCluskey et al. (1990), washed several times in 0.05 M EDTA and stored in the cold (approx. $4{ }^{\circ} \mathrm{C}$ ). Pulse-field electrophoresis was conducted in a Bio-Rad CHEF DRII apparatus at $84 \mathrm{~V}, 14^{\circ} \mathrm{C}$ for $72 \mathrm{~h}$, with the switching time increasing linearly from 120 to $900 \mathrm{~s}$.

DNA sequencing and design of taxon-specific primers. The ITS region and the D1/D2 divergent domains of rDNAs were amplified by the PCR. Whole yeast cells were used as sources of templates. Cells growing on YM agar (Difco) were suspended in sterile water to a density of ' $1+$ ' (Yarrow, 1998 ) and the suspension was added at a rate of $40 \%$ of the PCR volume. The amplification was conducted as recommended by the manufacturer of heat-activated Taq poly- merase (AmpliTaq Gold, Perkin-Elmer) in a Perkin-Elmer System 2400 cycler. After $9 \mathrm{~min}$ at $95^{\circ} \mathrm{C}$, the reaction mixture was subjected to 35 cycles of $94^{\circ} \mathrm{C}$ for $10 \mathrm{~s}$, various annealing temperatures for $10 \mathrm{~s}$ and $72^{\circ} \mathrm{C}$ for various extension times, as required. A final extension at $72^{\circ} \mathrm{C}$ for $7 \mathrm{~min}$ was followed by cooling to $4^{\circ} \mathrm{C}$. The annealing temperatures were dictated by the calculated hybridization melting temperatures of the primers (DNAMAN version 4.0; Lynnon BioSoft). When the melting temperatures of various primers (Table 2) used together differed significantly, the annealing temperature was ramped from the highest to the lowest value at the rate of $-0.2{ }^{\circ} \mathrm{C}$ per cycle and then remained constant for the remaining cycles. The extension time for separate amplification of D1/D2 or ITS regions was $20 \mathrm{~s}$. Screening of strains for the presence or absence of group-specific sequences involved the use of three primers (Fell, 1993). For forward specific primers located in the ITS2 spacer, the reference primers were IT1 and NL4 and the extension time was $30 \mathrm{~s}$, as the expected specific products were $0.7 \mathrm{~kb}$ long. For reverse specific primers located in the ITS1, the reference primers were IT1 and IT2 and the extension time was $5 \mathrm{~s}$, to favour amplification of the $0.05 \mathrm{~kb}$ products. The primers were purchased from Procyon BioPharma. 
For sequencing, the amplified DNA was concentrated and purified with MicroCon 100 concentrators (Amicon) or with Qiaquick PCR columns (Qiagen) and sequenced in an ABI sequencer at the John P. Robarts Research Institute (London, Ont.). The program CHROMAS 1.5 (Technelysium) was used to edit the sequence electrophoregrams. The program DNAMAN was used to align the sequences by CLUSTAL W (Thompson et al., 1994), to design primers and to construct neighbour-joining trees.

\section{RESULTS AND DISCUSSION}

\section{Provisional nomenclature}

The designations used in the following discussion are based on all the information reported in this paper, with special emphasis on rDNA sequences or reaction with specific primers. They will be justified after reviewing the data. We shall ultimately propose the division of the species complex into ten species, one of which contains three varieties. The origin of the names is as follows. 'Sporopachydermia cereana sensu stricto' applies to the species defined by Phaff et al. (1974) and Rodrigues de Miranda (1978) and further by Lachance \& Phaff (1998). The epithet 'oaxacaensis' applies to strains that originated from localities in three southern states of Mexico, Oaxaca being the most central. The designation 'stenocereana' applies to a single isolate from a Haitian columnar cactus. The epithet 'obscura' applies to strains isolated sporadically from various host plants and geographical locations in the tropical Americas. Strains in the 'australis' group were isolated in three South-American regions. The 'opuntiana' group comprises isolates that originated primarily from Australia, the south-eastern United States and the Caribbean, mostly from prickly pears. Two isolates unique to the Argentinian cardón cactus are referred to as 'trichocereana'. Four isolates from the Mexican state of Chiapas and two localities in Honduras were termed 'centralis' (Central America). Representatives of certain Brazilian isolates (Rosa et al., 1995) are designated 'brasiliensis'. An isolate from the Mexican cardón cactus is referred to as 'pachycereana'. Isolates from agave rots collected in the Mexican state of Jalisco (Lachance, 1995) are referred to as 'agaves' and an isolate from a red oak exudate in Ontario is termed 'paraquercuum'.

\section{Growth characteristics}

With minor exceptions, all known members of the Sporopachydermia clade assimilate D-xylose, ethanol, glycerol, myo-inositol and ethyl acetate as sole carbon

Table 3. Nucleotide base composition and DNA-DNA reassociation among selected strains of the Sporopachydermia cereana species complex

Results were obtained by the liquid-phase, hydroxyapatite method. Homologous reactions are shown in parentheses.

\begin{tabular}{|c|c|c|c|}
\hline \multirow[t]{2}{*}{ Strain } & \multirow[t]{2}{*}{ DNA G + C content $(\mathrm{mol} \%)$} & \multicolumn{2}{|c|}{ Reference strain } \\
\hline & & $\mathrm{D} 72-313^{\mathrm{T}}$ & D82-461A \\
\hline \multicolumn{4}{|c|}{ S. cereana sensu stricto } \\
\hline D72-313 ${ }^{\mathrm{T}}$ & $49 \cdot 3$ & $(100)$ & 10 \\
\hline D76-214C & $49 \cdot 2$ & 85 & \\
\hline D76-406C & $48 \cdot 5$ & 73 & \\
\hline D81-413C & $48 \cdot 7$ & 83 & \\
\hline D81-489B & $49 \cdot 6$ & 82 & \\
\hline D81-676.2 & $49 \cdot 4$ & 80 & \\
\hline \multicolumn{4}{|c|}{ 'oaxacaensis' } \\
\hline D77-321B & $48 \cdot 6$ & 32 & \\
\hline \multicolumn{4}{|c|}{ 'stenocereana' } \\
\hline D82-449B & $50 \cdot 4$ & 39 & \\
\hline \multicolumn{4}{|l|}{ 'obscura' } \\
\hline D82-520A & $45 \cdot 1$ & & 8 \\
\hline \multicolumn{4}{|l|}{ ‘opuntiana' } \\
\hline D77-33 & $42 \cdot 6$ & & 78 \\
\hline D81-645.3 & $42 \cdot 2$ & & 78 \\
\hline D82-424A & $42 \cdot 2$ & 8 & 53 \\
\hline D82-461A & $41 \cdot 8$ & & $(100)$ \\
\hline D82-571B & $41 \cdot 5$ & & 75 \\
\hline D82-611C & $41 \cdot 6$ & & 74 \\
\hline \multicolumn{4}{|c|}{ 'pachycereana' } \\
\hline D76-228A & $43 \cdot 5$ & 7 & 7 \\
\hline
\end{tabular}


sources and ethylamine and lysine as sole nitrogen sources. All grow at $30^{\circ} \mathrm{C}$ or higher and are resistant to at least $10 \mu \mathrm{g}$ cycloheximide $\mathrm{ml}^{-1}$. Vitamins are required for growth, but amino acids are not. Members of the Sporopachydermia cereana species complex differ from the rest of the clade (Sporopachydermia lactativora and Sporopachydermia quercuum) by their ability to assimilate erythritol as sole carbon source.

Within the species complex, the assimilation of trehalose, cellobiose, salicin, L-sorbose, D-arabinose, Dribose, 1-propanol, 2-propanol, 1-butanol, ribitol, xylitol, mannitol, glucitol, lactic acid, succinic acid, 2ketogluconic acid and acetone as carbon sources is variable, as are utilization of cadaverine as sole nitrogen source and resistance to $0.5 \%$ tannin, $75 \mu \mathrm{g}$ cetyldimethylethylammonium bromide (CTAB) $\mathrm{ml}^{-1}$, $500-1000 \mu \mathrm{g}$ cycloheximide $\mathrm{ml}^{-1}$ and $8 \mu \mathrm{g}$ digitonin $\mathrm{ml}^{-1}$. Weak utilization of L-arabinose may occur. Vegetative cells may be curved. Formation of ascospores is variable and occurs in single cultures grown on McClary's acetate agar. Sporulation was detected in several strains of Sporopachydermia cereana (all three varieties), a single strain of 'opuntiana' and both strains of 'trichocereana' (Table 1). Conjugation does not precede ascus formation, but in some cases cultures mixed in pairs undergo morphological distortions indicative of $\mathrm{G}_{1}$ arrest. This can also be visualized on a Petri dish by plating a lawn of target cells and spotinocula of inhibitory cells in a manner similar to that used for detection of killer toxins. Strains known to cause the inhibition or to be susceptible to it are indicated in Table 1. The inhibition was not specific, as most sensitive strains were inhibited by most inhibitor strains. The phenomenon appears to be independent of taxonomic position within the species complex. The optimum $\mathrm{pH}$ for these reactions is close to the optimum growth $\mathrm{pH}$ (about 5.5). We interpret this phenomenon as a remnant of a mating system that is no longer functional.

Taken together, the above properties do not clearly partition into groups of correlated responses on the basis of which the different taxa in the species complex can be defined. As will be shown below, even when the relatedness patterns among strains are known, the plasticity of many characters renders them nearly unusable for defining all taxa.

\section{DNA base composition}

The first indication that yeasts originally identified as Sporopachydermia cereana (or Cryptococcus cereanus) were not genetically homogeneous came from the determination of $\mathrm{G}+\mathrm{C}$ contents in their nuclear DNA. Representative values are given in Table 3. Four classes emerged, namely $49-50 \mathrm{~mol} \%$ for the type of the species and many similar strains, $41-42 \mathrm{~mol} \%$ for a very large number of isolates that fit in the 'opuntiana' group, $45 \mathrm{~mol} \%$ for an isolate of the 'obscura' group and $43.5 \mathrm{~mol} \%$ for the single isolate designated as 'pachycereana'. The other two described species of Sporopachydermia (Lachance \& Phaff, 1998) have values of $46 \mathrm{~mol} \%$ (Sporopachydermia lactativora) and $38 \mathrm{~mol} \%$ (Sporopachydermia quercuum).

\section{DNA-DNA reassociation}

DNA-DNA reassociation experiments (Table 3) confirmed the existence of four genetically distinct units and further indicated that the $49-50 \mathrm{~mol} \% \mathrm{G}+\mathrm{C}$ strains in fact represent three separate populations, namely Sporopachydermia cereana sensu stricto plus strains designated as 'oaxacaensis' and 'stenocereana'. One 'opuntiana' isolate (D82-424A) also appeared distinct from the rest, based on a $53 \%$ reassociation value.

\section{Electrokaryotypes}

Electrophoretic karyotypes for 60 strains are shown in Fig. 1. The patterns are characterized by the presence of four or more bands, many of which represent chromosomal DNAs that are larger than those of Saccharomyces cerevisiae. Although the patterns did not always allow each strain to be positioned within a group, they were useful in identifying replicate isolates or closely related strains and they allowed certain strains to be excluded as potential close relatives (e.g. the pattern for 'paraquercuum' was substantially different from all others). Note, however, the important variation observed in some groups, for example 'obscura'.

\section{Sequence analyses}

In view of the perplexing picture emerging from the above data, rDNA sequencing was applied to the resolution of the phylogenetic group structure in Sporopachydermia. One objective was to find indicator sequences and to use these to design group-specific primers that could be used to identify unknowns rapidly. Two important assumptions underlie this approach, namely (i) that strains that respond positively to a specific primer have essentially the same sequence as the reference strain and (ii) that the phylogeny of the rDNA reflects the history of the taxon (orthology).

In a preliminary test, $\mathrm{D} 1 / \mathrm{D} 2$ divergent domains of the large subunit rDNA were examined in the type of Sporopachydermia cereana (sequence from Kurtzman \& Robnett, 1998), members of the closely related 'oaxacaensis' and 'stenocereana' designations and the more distant strains D82-520A and D76-228A, representing 'obscura' and 'pachycereana' (at least one member of each group was eventually sequenced, Fig. 2 ). The inter-strain divergence values among the five sequences varied from 0.5 to $2.5 \%$, but the variation was dispersed along the entire length of the D1/D2 domains, making the design of specific probes impractical. We therefore turned to the more variable 

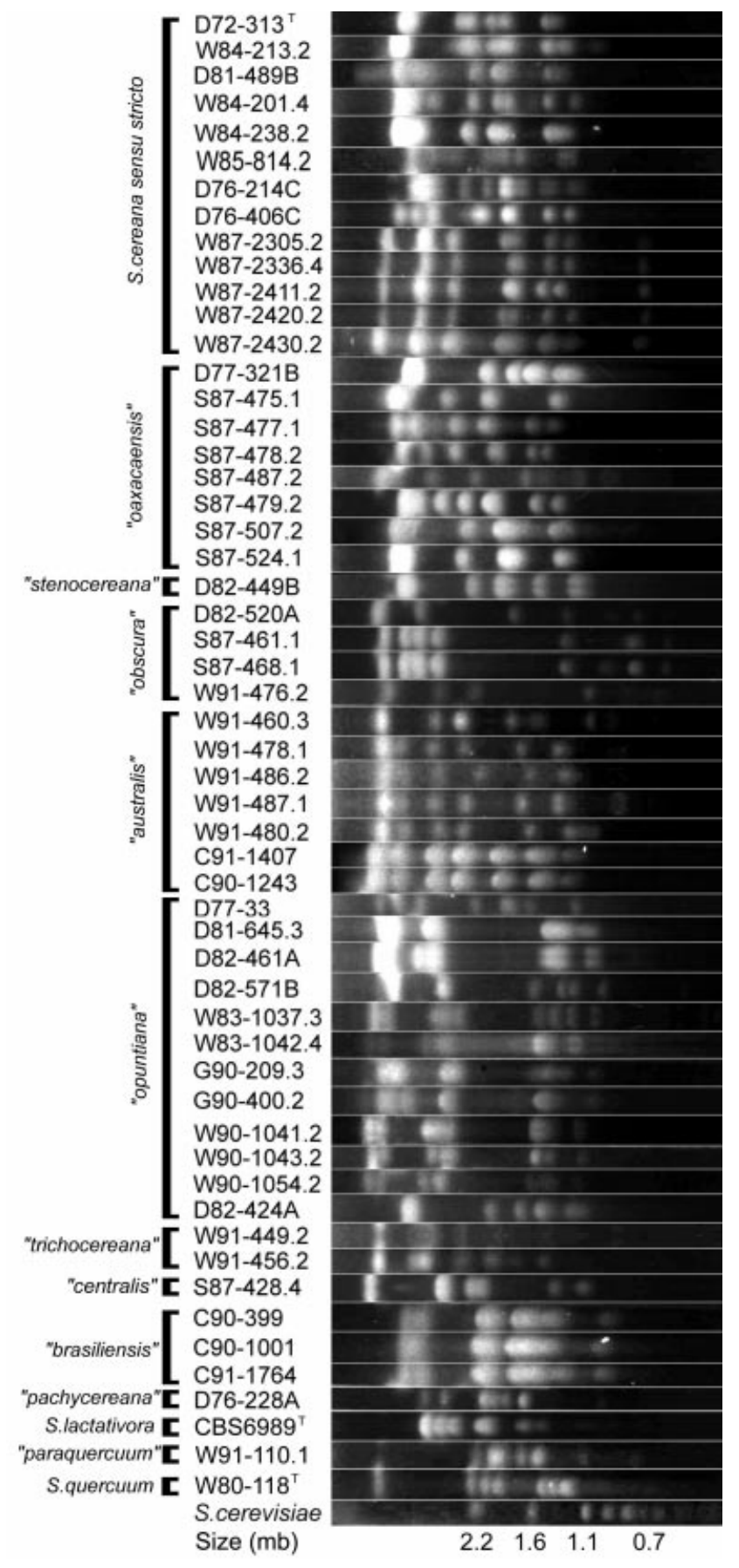

Fig. 1. Electrophoretic karyotypes of selected strains in the Sporopachydermia cereana species complex. See Methods for details. Saccharomyces cerevisiae (Bio-Rad standard) was used for comparison.

internal transcribed spacer (ITS) region. Strains D72313 ${ }^{\mathrm{T}}$, D77-321B, D82-449B, D82-520A, W91-478.1, D82-461A, W91-456.2, S87-428.4, D76-228A, CBS $6989^{\mathrm{T}}$ (type strain of Sporopachydermia lactativora) and $\mathrm{W} 80-118^{\mathrm{T}}$ (type strain of Sporopachydermia quercuum) were sequenced first. Although the $5.8 \mathrm{~S}$ gene was invariant in all strains, the minimum di-

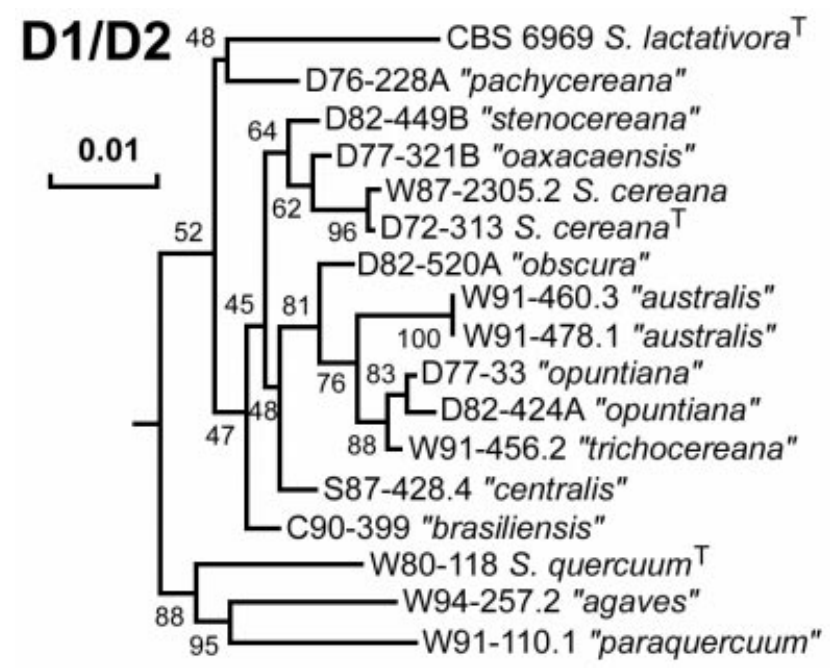

Fig. 2. Phylogeny of the Sporopachydermia clade based on sequences of the D1/D2 region of the rDNA. The trees were constructed by neighbour-joining. Bootstrap values for 1000 iterations are shown as percentages. Bar, $1 \%$ DNA divergence.

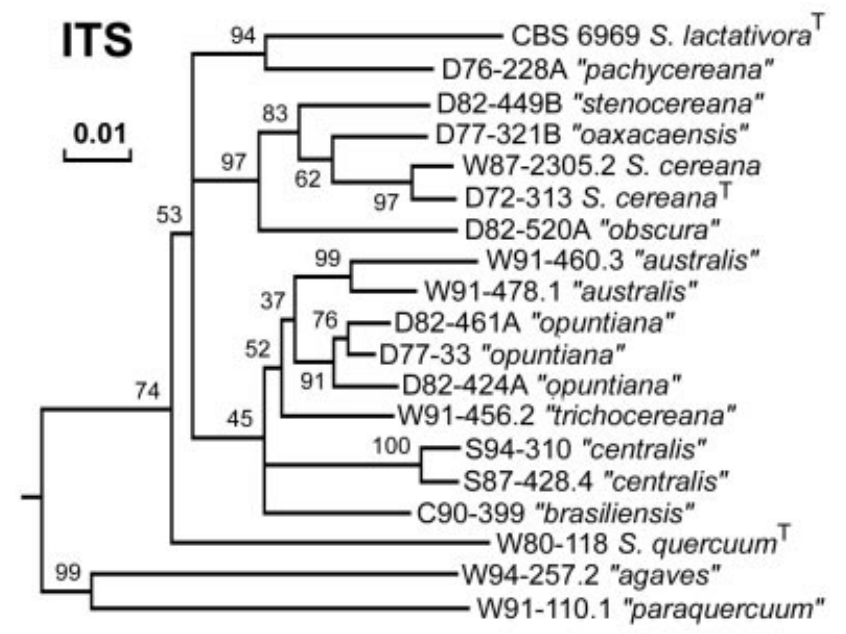

Fig. 3. Phylogeny of the Sporopachydermia clade based on sequences of the ITS region of the rDNA. The trees were constructed by neighbour-joining. Bootstrap values for 1000 iterations are shown as percentages. Bar, $1 \%$ DNA divergence.

vergence between strains shown to be genetically distinct by DNA reassociation was $1.3 \%$ for the entire ITS cluster (ITS1-5.8S-ITS2), indicating that sufficient variation existed to discriminate between groups (Fig. 3). Primers IT3 to IT7 were designed and used sequentially, allowing the progressive assignment of most strains into groups without the need to sequence them all. Primers specific to the last eight taxa in Table 1 were not necessary, because these taxa could be identified either on the basis of other properties or by sequencing, being represented by only a few strains. 
The ITS regions of additional strains (Fig. 3) were sequenced for the following reasons. In the 'opuntiana' group, only the homologous reaction (strain D82461A) gave a clear positive result by the three-primer method. Other members gave a weak signal for the specific primer pair as well as a weak but clear signal for the reference pair. The sequence of strain D77-33 was therefore determined and found to differ by $1.3 \%$ from that of the reference strain (D82-461A), with a two-base inversion in the priming site. In view of this result and of the $53 \%$ DNA-DNA reassociation value obtained between strains D82-461A and D82-424A (Table 3), the latter was also sequenced. Strains S82-653B and S86-242 (not included in Fig. 3) gave ambiguous reactions with primer IT4 and were sequenced. The pair-wise sequence divergence between the five sequenced strains in the 'opuntiana' group varied from 0.9 to $2.0 \%$, and variation existed in three adjacent bases located in the IT4 priming site. However, the phylogenetic analysis of the aligned ITS sequences showed that they belong to the same clade (the three most divergent representatives are included in Fig. 3).

On the basis of other data, the Hawaiian isolates (represented by strains W87-2305.2 and W87-2326.3) had been assigned to Sporopachydermia cereana sensu stricto. However, they gave negative results with primer IT3 and weak reactions with primer IT7 (specific to 'oaxacaensis'). Sequencing (Fig. 3) confirmed that strain W87-2305.2 is indeed more closely related to strain D72-313 ${ }^{\mathrm{T}}$ (Sporopachydermia cereana sensu stricto, $1.3 \%$ divergence) than to strain D77321B ('oaxacaensis', $3 \cdot 1 \%$ divergence). The failure of primer IT3 to react with DNAs of strain W87-2305.2 and other Hawaiian isolates was caused by four substitutions near the $3^{\prime}$ end of the primer sequence and the false-positive reaction with primer IT7 reflected the fact that this primer shared nine identical bases at the $3^{\prime}$ end with the target site in strain W87-2305.2. Strains for which there was a clear positive signal for primer IT7 and a negative control signal were assigned to 'oaxacaensis'.

Strain W91-460.3 reacted both with primer IT6 (specific to 'australis') and with the control primers. Sequencing showed that the priming site of the strain differed from that of the reference strain (W91-478.1) by two substitutions and the overall ITS region differed by $2.9 \%$, mostly due to a 15 base insertion in the ITS 2 (which accounts for the longer branch for strain W91-460.3 in Fig. 3). However, the topology of the phylogram of the ITS region suggested that strain W91-460.3 belongs to the 'australis' clade, and the D1/D2 domains of the two strains were identical (Fig. 2).

Three isolates from a Brazilian columnar cactus responded to none of the group-specific primers and shared distinct electrophoretic karyotypes and assimilation profiles. The ITS and D1/D2 sequences of the representative strain C $90-399$ differed by $5 \cdot 0 \%$ and
$1 \cdot 1 \%$, respectively, from those of any other strain sequenced (Fig. 3). Some recent isolates from agave had not been characterized by karyotyping or DNA reassociation, but were identified as Sporopachydermia-like on the basis of growth tests. Their DNAs did not react with any of the group-specific primers. These strains and a single isolate from red oak exudate ('paraquercuum') exhibited growth responses similar to those of 'brasiliensis'. The pair-wise sequence differences between a representative from 'agaves' and one from 'brasiliensis' were $12.5 \%$ in the ITS and $2.7 \%$ in the D1/D2 regions, the highest divergence values obtained between these strains and any others.

\section{Taxonomic interpretation}

Faced with the task of assigning members of the Sporopachydermia cereana species complex to meaningful taxonomic units in the absence of clear heterothallic sexuality, we integrated the results obtained by various molecular approaches. A difference of $1.5 \%$ in DNA base composition determined by analytical ultracentrifugation has generally been interpreted as clear evidence for species delineation (Kurtzman, 1998). On that basis, we recognized the 'obscura', 'opuntiana' and 'pachycereana' designations as representatives of distinct species, separate from Sporopachydermia cereana sensu stricto. Although a $1 \%$ difference in base composition left the position of the 'obscura' group as distinct from Sporopachydermia lactativora in doubt, the matter was resolved by sequence analysis.

Numerous accounts have indicated that strains exhibiting $60 \%$ or more DNA reassociation can be regarded as conspecific (Kurtzman, 1998). Lower but non-trivial values, e.g. $25-60 \%$, have generally but not always been associated with different varieties or even species, depending on other features relevant to the ability of yeasts to share effectively a common gene pool. The reassociation values of 32 and $39 \%$ obtained for the 'oaxacaensis' and 'stenocereana' designations (Table 3) are therefore problematic. The 'oaxacaensis' group is indistinguishable from Sporopachydermia cereana sensu stricto by growth characteristics. Conversely, strain D82-449B ('stenocereana') differs in the assimilation of glucitol and is the only digitoninresistant strain in the Sporopachydermia clade. On the basis of DNA reassociation, strain D82-424A would appear to represent a genetic variety of the 'opuntiana' group, with a DNA reassociation value of $53 \%$ from the reference strain, but it is otherwise indistinguishable.

Kurtzman \& Robnett (1998) published the D1/D2 sequences of all ascomycetous yeasts known at that time and new sequences are continuously being made available by various authors describing new species. This has allowed the formulation of certain generalizations on the significance of sequence divergence in species delineation, namely (i) that con- 
specific strains seldom differ by more than three bases in their D1/D2 region and (ii) that strains differing by $1 \%$ (five or six bases) or more over this region are likely to be different species. A similar set of guidelines is not yet available for the ITS region, because a database of ITS sequences is only starting to accumulate. Five varieties of Williopsis saturnus examined by James et al. (1998) differed by only a few bases in the ITS regions. A similar situation exists among most physiological variants of Saccharomyces cerevisiae and Saccharomyces bayanus, but the two species are clearly distinct, differing by $2 \%$ or more in the ITS/5.8S region (Montrocher et al., 1998). Species of Zygosaccharomyces and Torulaspora that are closely related on the basis of small subunit rDNA sequences (James et al., 1996) exhibited various degrees of ITS divergence, ranging from almost none to nearly $40 \%$ in the ITS1 and $50 \%$ in the ITS2.

In the Sporopachydermia clade, D1/D2 and ITS/5.8S divergence values are loosely correlated $(r=0.73)$. Independent isolates that were nearly identical in their D1/D2 domains exhibited as much as 3\% divergence in the ITS $/ 5.8 \mathrm{~S}$ region. The highest divergence values within the clade were approximately $14 \%$ for the ITS/5.8S region, corresponding to approximately $5 \%$ in the D1/D2 domains. By contrast, the divergence between Sporopachydermia cereana and Saccharomyces cerevisiae is $21 \%$ for D1/D2 and 27\% for ITS $/ 5.8 \mathrm{~S}$. A comparison between ITS $/ 5.8 \mathrm{~S}$ divergence and DNA-DNA reassociation data $(r=$ $0.97)$ predicted that strains that give reassociation values of $100 \%$ are likely to be nearly identical in their ITS regions. It is interesting to note that Sporopachydermia lactativora and Sporopachydermia quercuum were found to be identical in a 168 base sequence located at the $3^{\prime}$ end of the small (16-18S) rDNA subunit that has been used by some as a phylogenetic marker (Yamada et al., 1992).

Considering the data as a whole, the most prudent interpretation in the present context is that Sporopachydermia cereana consists of three varieties, 'cereana', 'oaxacaensis' and 'stenocereana', and that all other designations represent distinct species. Strain D82-424A is provisionally considered an outlier within 'opuntiana'. Formal descriptions of these taxa by the authors involved in their respective discoveries will be forthcoming.

\section{Biogeography and community structure}

The distribution of the various members of the Sporopachydermia cereana complex appears to be based principally on geography and less on host-plant specificity (Table 1). Other members of the yeast community associated with cactus necroses are known to exhibit varying degrees of geographical or host partitioning (Starmer et al., 1990). For example, Pichia cactophila belongs to a clade of eight cactophilic taxa (Kurtzman \& Robnett, 1998), some of which are distributed globally in all cactus species (e.g. $P$. cactophila itself), whereas others may be specific to a particular host plant and geographical region (e.g. Pichia heedii is restricted to the Sonoran region, mostly in cacti of the subtribe Pachycereinae). Candida sonorensis is isolated from cacti everywhere and is thought to be genetically homogeneous; the growth test responses are singularly invariant and they exhibit low DNA polymorphism when compared by arbitrary primer amplification (P. F. Ganter, personal communication). Clavispora comprises two species, one of which (Clavispora lusitaniae) is dominant in agave rots (Lachance, 1993) and regularly recovered from a broad range of other sources (Holzchu et al., 1979), including cacti (Lachance et al., 1986). The other (Clavispora opuntiae) occurs in cacti worldwide and the various genotypes within the species are distributed in certain geographical patterns (Lachance, 1990; Lachance et al., 2000).

No members of the Sporopachydermia cereana species complex appear to be truly cosmopolitan. The findings that Hawaiian strains belong to the same genetic group as those in the Sonoran region and that the 'opuntiana' group occupies Australia and the Caribbean region are both consistent with the known history of anthropogenic cactus dispersal (Dodd, 1940; Fullaway, 1954). The elucidation of a species ('australis') the known range of which spans South America also makes sense, but the discovery of taxa that appear to be specific to more confined localities in Central America, Baja California, Haiti or Brazil is more puzzling, especially when juxtaposed with the recovery of 'obscura' strains in five distinct localities and four different host plant species (Table 1). Adding to this the existence of the species 'paraquercuum' in temperate oaks, the emerging suggestion is that the biodiversity of the species complex is much more complicated than anticipated and that further sampling of new habitats is likely to yield a large number of new taxa belonging to the group.

The broader distribution of 'obscura' raised the question of homogeneity within the species, since membership of the species was inferred from a specific primer with a relatively short recognition sequence. For this reason, the ITS regions of three additional strains, each from a different geographical origin, were sequenced (Table 1). The three sequences were identical and differed by a single substitution from that of strain D82-520A, the only representative of 'obscura' included in Fig. 3.

The interconnection between phylogeny and geography is also interesting from the standpoint of taxon overlap. Specifically, it appears that Sporopachydermia cereana sensu stricto and the species 'opuntiana', the two most abundant taxa, are separated geographically. The exception is the recovery of a rare strain (D81676.2) of Sporopachydermia cereana sensu stricto in a Texan cactus sample (Table 1). Likewise, the three varieties of Sporopachydermia cereana appear mu- 
Table 4. Selected characteristics of genetic groups within the Sporopachydermia cereana species complex

The genetic groups are identified as: 1, Sporopachydermia cereana; 2, 'oaxacaensis'; 3, 'stenocereana'; 4, 'obscura'; 5, 'australis'; 6, 'opuntiana'; 7, 'trichocereana'; 8, 'centralis'; 9, 'brasiliensis'; 10, 'pachycereana'; 11, 'agaves'; 12, 'paraquercuum'. The tests are ranked in decreasing order of discriminatory power. Growth is classified as: -, no growth; s, slow; v, variable; w, weak; +, positive.

\begin{tabular}{|c|c|c|c|c|c|c|c|c|c|c|c|c|}
\hline Growth test & 1 & 2 & 3 & 4 & 5 & 6 & 7 & 8 & 9 & 10 & 11 & 12 \\
\hline Digitonin & - & - & + & - & - & - & - & - & - & - & - & - \\
\hline Glucitol & + & + & - & $\mathrm{W}$ & + & + & + & + & - & - & - & - \\
\hline Mannitol & + & + & + & - & + & + & + & + & - & - & - & - \\
\hline Salicin & + & $\mathrm{V}$ & - & - & + & - & - & - & - & - & - & - \\
\hline Cadaverine & + & + & + & + & + & + & + & + & + & - & + & + \\
\hline Tannin & - & - & - & - & - & - & - & - & - & - & $\mathrm{V}$ & + \\
\hline CTAB $\left(75 \mathrm{mg} \mathrm{l}^{-1}\right)$ & + & + & + & - & - & + & $\mathrm{V}$ & $\mathrm{W}$ & - & $\mathrm{s}$ & - & - \\
\hline 2-Propanol & $\mathrm{V}$ & $\mathrm{w}$ & $\mathrm{S}$ & $\mathrm{W}$ & W & $\mathrm{V}$ & w & $\mathrm{W}$ & $\mathrm{S}$ & $\mathrm{W}$ & $\mathrm{S}$ & $\mathrm{s}$ \\
\hline Trehalose & + & + & - & - & + & $\mathrm{V}$ & - & - & $\mathrm{s}$ & - & + & + \\
\hline Ribitol & + & + & $\mathrm{w}$ & $\mathrm{V}$ & $\mathrm{S}$ & $\mathrm{V}$ & + & + & $\mathrm{w}$ & $\mathrm{W}$ & $\mathrm{V}$ & - \\
\hline
\end{tabular}

tually exclusive in their distributions in the Sonoran region, southern Mexico and Haiti. In South America, the species 'australis' appears to replace both 'cereana' and 'opuntiana' as the dominant species. Since there is no obvious association between yeast taxon and hostplant species, it would be difficult to implicate host plant chemistry as a determining factor. Perhaps this is a case where vicariance is a better explanation than dispersal for the observed distribution of taxa. Likewise, the growth inhibition of some strains by others (Table 1) does not follow geographical or even phylogenetic lines that could explain mutual exclusion of taxa. The possibility remains that members of the Sporopachydermia cereana species complex have alternate hosts that are region-specific and that the occurrence of these yeasts in cacti is accidental. We have no empirical evidence yet that this might be the case. When yeasts were collected from necrotic somatic tissue in the Caribbean in 1983 (Starmer et al., 1987) and in Florida in 1985 (Starmer et al., 1988), samples were also taken from decaying cactus fruit. These did not yield any cultures related to Sporopachydermia.

\section{Identification}

We have assessed carefully the usefulness of growth responses that exhibit variation within the Sporopachydermia cereana species complex. The most informative responses are listed in Table 4 in decreasing order of discriminatory power (between-group versus within-group variance). Most are insufficient to provide a clear definition of many of the taxa identified by DNA analyses. Identification will have to take into account the sources of isolation and may necessitate the use of group-specific primers or sequencing. In some cases, the maximum growth temperature allows a clear differentiation of taxa. For example, Sporopachydermia cereana sensu stricto generally grows at $45^{\circ} \mathrm{C}$ or above, whereas 'opuntiana' strains rarely grow above $42{ }^{\circ} \mathrm{C}$. However, determination of maximum growth temperature is not entirely reproducible from one laboratory to another, due to variation in the equipment used to measure and control temperature, as well as in the culture conditions (e.g. broth versus agar, complex versus defined media). For this reason, these traits were not considered in the present analysis.

\section{ACKNOWLEDGEMENTS}

This work was funded by the Natural Science and Engineering Research Council of Canada (M.-A.L.) and the National Science Foundation, USA (H. J.P., W.T.S.). Some later collections were made possible through two cruises on the University of Miami research vessel Calanus (J.W. Fell). Permission to collect from agave plants on the estates of Tequila Herradura SA de CV, Amatitan, Mexico, is gratefully acknowledged. We thank D. Cornejo, P.F. Ganter, R. Metsger, F. Peris and C.A. Rosa for the gift of strains or collection assistance, I. Goodman for laboratory assistance and P. Campbell and H. Schneider for sequence determinations.

\section{REFERENCES}

Dodd, A. P. (1940). The Biological Campaign against Prickly Pear. Brisbane: Commonwealth Prickly Pear Board.

Fell, J. W. (1993). Rapid identification of yeast species using three primers in a polymerase chain reaction. Mol Mar Biol Biotechnol 2, 174-180.

Fullaway, D. T. (1954). Biological control of cactus in Hawaii. $J$ Econ Entomol 47, 696-700.

Holzschu, D. L., Presley, H. L., Miranda, M. \& Phaff, H. J. (1979). Identification of Candida lusitaniae as an opportunistic yeast in humans. J Clin Microbiol 10, 202-205.

James, S. A., Collins, M. D. \& Roberts, I. N. (1996). Use of an rRNA internal transcribed spacer region to distinguish phylogenetically closely related species of the genera Zygo- 
saccharomyces and Torulaspora. Int J Syst Bacteriol 46, 189-194.

James, S. A., Roberts, I. N. \& Collins, M. D. (1998). Phylogenetic heterogeneity of the genus Williopsis as revealed by the $18 \mathrm{~S}$ rRNA gene sequences. Int $J$ Syst Bacteriol 48, 591-596.

Kurtzman, C. P. (1998). Nuclear DNA hybridization: quantitation of close relationships. In The Yeasts, a Taxonomy Study, 4th edn, pp. 63-68. Edited by C. P. Kurtzman \& J. W. Fell. Amsterdam: Elsevier.

Kurtzman, C. P. \& Robnett, C. J. (1998). Identification and phylogeny of ascomycetous yeasts from analysis of nuclear large subunit (26S) ribosomal DNA partial sequences. Antonie Leeuwenhoek 73, 331-371.

Lachance, M.-A. (1990). Ribosomal DNA variation in the cactophilic yeast Clavispora opuntiae. Mol Biol Evol 7, 178-193.

Lachance, M.-A. (1993). Metschnikowia agaveae, a haploid, heterothallic yeast species from blue agave. Can J Microbiol 39, $562-566$.

Lachance, M.-A. (1995). Yeast communities in a natural tequila fermentation. Antonie Leeuwenhoek 68, 151-160.

Lachance, M.-A. \& Phaff, H. J. (1998). The genus Sporopachydermia. In The Yeasts, a Taxonomy Study, 4th edn, pp. 398-402. Edited by C. P. Kurtzman \& J. W. Fell. Amsterdam: Elsevier.

Lachance, M.-A., Phaff, H. J., Starmer, W. T., Moffitt, A. \& Olson, L. G. (1986). Interspecific discontinuity in the genus Clavispora Rodrigues de Miranda by phenetic analysis, genomic deoxyribonucleic acid reassociation, and restriction mapping of ribosomal deoxyribonucleic acid. Int $J$ Syst Bacteriol 36, 524-530.

Lachance, M.-A., Starmer, W. T. \& Phaff, H. J. (1988). Identification of yeasts found in decaying cactus tissue. Can $J$ Microbiol 34, 1025-1036.

Lachance, M.-A., Starmer, W. T., Bowles, J. M., Phaff, H. J. \& Rosa, C. A. (2000). Ribosomal DNA, species structure, and biogeography of the cactophilic yeast Clavispora opuntiae. Can J Microbiol 46, 195-210.

McCluskey, K., Russell, B. W. \& Mills, D. (1990). Electrophoretic karyotyping without the need for generating protoplasts. Curr Genet 18, 385-386.

Montrocher, R., Verner, M.-C., Briolay, J., Gautier, C. \& Marmeisse, R. (1998). Phylogenetic analysis of the Saccharomyces cerevisiae group based on polymorphisms of rDNA spacer sequences. Int J Syst Bacteriol 48, 295-303.
O'Donnell, K. (1993). Fusarium and its near relatives. In The Fungal Holomorph: Mitotic, Meiotic and Pleomorphic Speciation in Fungal Systematics, pp. 225-233. Edited by D. R. Reynolds \& J. W. Taylor. Wallingford: UK: CAB International.

Phaff, H. J., Miller, M. W., Miranda, M., Heed, W. B. \& Starmer, W. T. (1974). Cryptococcus cereanus, a new species of the genus Cryptococcus. Int J Syst Bacteriol 24, 486-490.

Price, C. W., Fuson, G. B. \& Phaff, H. J. (1978). Genome comparison in yeast systematics: delimitation of species within the genera Schwanniomyces, Saccharomyces, Debaryomyces, and Pichia. Microbiol Rev 42, 161-193.

Rodrigues de Miranda, L. (1978). A new genus: Sporopachydermia. Antonie Leeuwenhoek 44, 439-450.

Rosa, C. A., Morais, P. B., Santos, S. R., Peres Neto, P. R., Mendonça-Hagler, L. C. \& Hagler, A. N. (1995). Yeast communities associated with different plant resources in the sandy coastal plains of southeastern Brazil. Mycol Res 99, 1047-1054.

Starmer, W. T., Lachance, M.-A. \& Phaff, H. J. (1987). A comparison of yeast communities found in necrotic tissue of cladodes and fruits of Opuntia stricta on islands in the Caribbean Sea and where introduced into Australia. Microb Ecol 14, 179-192.

Starmer, W. T., Aberdeen, V. \& Lachance, M.-A. (1988). The yeast community associated with decaying Opuntia stricta (Haworth) in Florida with regard to the moth, Cactoblastis cactorum (Berg). Florida Scientist 51, 7-11.

Starmer, W. T., Lachance, M.-A., Phaff, H. J. \& Heed, W. B. (1990). The biogeography of yeasts associated with decaying cactus tissue in North America, the Caribbean, and northern Venezuela. Evol Biol 24, 253-296.

Thompson, J. D., Higgins, D. G. \& Gibson, T. J. (1994). CLUSTAL $\mathrm{W}$ : improving the sensitivity of progressive multiple sequence alignment through sequence weighting, position-specific gap penalties and weight matrix choice. Nucleic Acids Res 22, 4673-4680.

Yamada, Y., Maeda, K., Nagahama, T., Banno, I. \& Lachance, M.-A. (1992). The phylogenetic relationships of the genus Sporopachydermia Rodrigues de Miranda (Saccharomycetaceae) based on the partial sequences of $18 \mathrm{~S}$ and $26 \mathrm{~S}$ ribosomal RNAs. J Gen Appl Microbiol 38, 179-183.

Yarrow, D. (1998). Methods for the isolation and identification of yeasts. In The Yeasts, a Taxonomy Study, 4th edn, pp. 77-100. Edited by C. P. Kurtzman \& J. W. Fell. Amsterdam: Elsevier. 